Growth factor technology has moved very quickly from the laboratory to the bedside, and it is too early to reach any firm conclusions. Probably the most effective way of using growth factors will be in combination as many have been shown to be synergistic in vitro and in preclinical studies. ${ }^{15}$ New factors are being identified and include molecules that act as negative regulators of the activity of haemopoietic stem cells, ${ }^{21}$ thus opening up the possibility of protecting normal cells from the effects of cytotoxic treatment. The ultimate place of growth factors in cancer medicine will be determined only from properly controlled trials with clinical end points-not by inferring benefit from changes in blood counts alone.

ASIM KHWAJA Wellcome Research Fellow ANTHONY H GOLDSTONE Consultant

Department of Haematology,

University College and Middlesex School of Medicine,

University College Hospital,

London WC1E 6AU

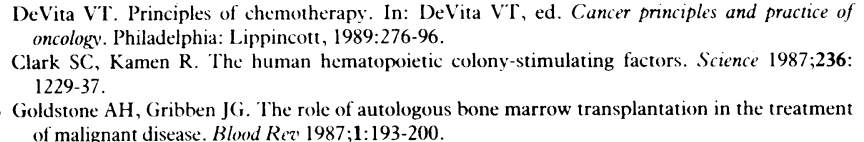

accelerates neutrophil recovery after autologous bone marrow transplantation for Hodgkin's disease. Bone Marrow Transplant 1989;4:49-54.

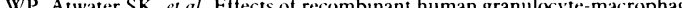
N

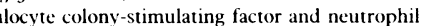
recovery after high-dose chemotherapy and autologous bone marrow transplantation. Lancel 1989;ii:891-5.

7 Goldstone $\mathrm{AH}, \mathrm{Khwaja} \mathrm{A}$. The role of haemopoietic growth factors in bone marrow transplantation. - Leuk Res 1990;14:721-30.

8 Morstyn G, Campbell L, Souza LM, et al. Effect of granulocyte colony-stimulating factor on neutropenia induced by cytotoxic chemotherapy. Lancet $1988 ; 1: 667-72$.

9 Cébon J, Dempsey P, Fox R, et al. Pharmacokinetics of human granulocyte-macrophage colonystimulating factor using a sensitive immunoassay. Blood 1988;72:1340-7.

10 Gribben JG, Devereux S, Thomas NSB, et al. Development of antibodies to unprotected glycosylation sites on recombinant human GM-CSF. Lancet 1990;335:434-7.

1 Baldwin GC, Gasson JC, Kaufman SE, et al. Nonhematopoietic tumour cells express functional GM-CSF receptors. Blood 1989;73:1033-7.

12 Salmon SE, Liu R. Effects of granulocyte-macrophage colony-stimulating factor on in vitro growt of human solid tumors. 7 Clin Oncol 1989:7:1346-50.

3 Brochud $\mathrm{MH}$ Scarfe $\mathrm{JH}$. Thather $\mathrm{N}$, et al. Phase $\mathrm{U} / \mathrm{U}$ study of recombinant human granulocyte colony stimulating factor in patients receiving intensive chemotherapy for small cell lung cancer. Br f Cancer 1987;56:809-13.

14 Herrmann F, Schulz G, Wieser M, et al: Effect of granulocyte-macrophage colony stimulating factor on neutropenia and related morbidity induced by myelotoxic chemotherapy. Am $\mathrm{f}$ Med 1990;88:619-24.

15 Devereux S, Linch DC. Present status of haemopoietic growth factors. Qf Med 1990;75:537-50. 6 Ganser A, Lindemann A, Ottman OG, et al. Effect of recombinant human interleukin-3 in vivo -a phase 1 trial. Exp Hematol 1989;17:40.

7 Medenica R, Huschart T. Erythropoietin prevents anemia in chemotherapy cancer patients. Bloo 1990;76(suppl 1):154a.

8 Jaswon MS, Khwaja A, Jones HM, Roberts PJ, Linch DC. The effect of rhGM-CSF on the neutrophil respiratory burst in whole blood. Br f Haematol 1990;75:181-7.

9 Khwaja A, Johnson B, Addison IE, et al. In vivo effects of macrophage colony stimulating factor on human monocyte function. Br F Haematol 1991;77:25-31.

20 Addison IE, Johnson B, Devereux S, Goldstone AH, Linch DC. Granulocyte-macrophage colony stimulating factor may inhibit neutrophil migration in vivo. Clin Exp Immunol 1989;76:149-53.

Graham GJ, Wright EG, Hewick R, et al. Identification and characterization of an inhibitor of haemopoietic stem cell proliferation. Nature 1990;334:4+2-4.

\title{
Taking pains to take away pain
}

\section{Time for hospitals to set up an acute pain service}

The inadequacy of postoperative pain relief is shameful. But, for at least a decade, drawing attention to the inadequacies of current practice has provoked a familiar response: if only enough people were available to minister to our patients' suffering any one of several approaches could provide very satisfactory comfort. This is no longer good enough. Pain After Surgery, commissioned jointly by the Royal College of Surgeons and the College of Anaesthetists, suggests how things may be improved, here and now.

Basic physiological and pharmacological research continues to emphasise the plasticity and diversity of nociception, ${ }^{2}$ and prospects for a "magic bullet"are no closer. Applying present knowledge more conscientiously promises more immediate therapeutic returns. Testing the many permutations and combinations of promising options requires many patients and much patience because the central assessments - pain and pain relief-are inherently imprecise. It is no work for university departments pressed for short term returns, but it does lend itself to perseverance in a well audited clinical setting.

The conventional approach to relieving severe postoperative pain is to give intermittent intramuscular injections of opioids at doses determined by medical guesswork and intervals determined by nursing expediency. Newer approaches address themselves to the limitations of this approach - for example, patient controlled analgesia with doses of systemic opioids tailored to the patient's individual perceptions of pain. ${ }^{3+}$ But modestly supraoptimal doses are liable to impair ventilatory responsiveness, particularly to obstructive challenges. Depending on the severity of the pain, prostaglandin synthetase inhibitors may partially or completely replace opioids, but alternative or additional drugs have their own risks, and the therapeutic index of the replacement or combination may not necessarily be improved.
Various forms of regional analgesia attempt to circumvent the limited therapeutic index of opioids given systemically. Intrathecal or epidural administration of opioids is intended to bathe target segments of the spinal cord with opioid-laden cerebrospinal fluid while the systemic concentrations remain low. ${ }^{5}$ The unpredictable mobility of the cerebrospinal fluid may, however, cause the brain stem to be bathed as well and stop breathing. The unpredictability of a rare catastrophe is perceived as more dangerous than the familiar ventilatory depression with systemic opioids. The conventional wisdom is not to use intrathecal or epidural opioids in patients who cannot be closely nursed: consequently very effective pain relief is withheld from most patients undergoing major surgery.

But all concerted attacks on severe postoperative pain carry risks that are too big to neglect but too small to quantify easily. Sufficiently confident estimates of relative risk have not been made to justify strong statements about either the relative merits of different analgesic approaches or the effectiveness of optimal analgesia in reducing mortality, morbidity, or the costs of treatment. Conventional approaches tend to be favoured by default. It is probably also true, however, that the inherent risks of each approach are much smaller than the avoidable risks arising from the failure of equipment, human error, poor communication, and poor education. Some anaesthetists feel under pressure to provide more effective pain relief by using more aggressive measures. Pain After Surgery endorses guidelines that are emerging to reduce the recognised risks of using such measures.

Because pain that has been recorded is less easily ignored assessments of pain should be included in the regular recording of vital signs. Once an analgesic approach is chosen it should be put into effect meticulously. Clear prescriptions for continuing management should be backed up by clear 
standing orders and contingency plans, by on call expert advice and assistance, and by a programme of continuing education to cater for the rapid turnover of junior nursing and medical staff on general surgical wards. The whole process should be supervised by consultants. This all adds up to providing an acute pain service.

The best publicised example of such a service is in North America, in a system of health care in which the cost can be passed on directly to the customer. ${ }^{6}$ Recognising that the resources for such a complete answer are not imminently available in the United Kingdom, Pain After Surgery recommends affordable measures that could be implemented soon and that would be amply repaid not least in comfort for the consumer. Most of its guidelines could be set in place if each hospital designated and empowered a willing person to do this. Such a person could also ensure that simple, inexpensive ancillary measures such as psychological preparation ${ }^{7}$ and provision for pre-emptive analgesia ${ }^{8}$ were not neglected and that nurses and pharmacists were properly integrated into the service.

The language of Pain After Surgery suggests that it is not only addressing doctors and nurses but is also appealing to the public to be less long suffering and to managers of purchaser units to respond to consumer demand for better pain relief. The report will be an important influence on our health service through and beyond the present period of change. When colleges come to assess and accredit hospitals for training in anaesthesia and surgery they will be noticing whether the recommendations of Pain After Surgery have been implemented.

Senior Lecturer in Anaesthesia,

A M S BLACK

Bristol Royal Infirmary,

Bristol BS2 8HW

1 Royal College of Surgeons and College of Anaesthetists. Pain a fter surgerv. Report of the working part of the commission on the provision of surgical services. London: Royal College of Surgeons and Colleg of Anaesthetists, 1990.

2 Woolf CJ. Recent advances in the pathophysiology of postoperative pain. Br $\mathcal{F}$ Anaesth 1989;63: $139-46$.

Mather LE, Owen $\mathrm{H}$. The scientific basis of patient-controlled analgesia. Anaesth Intensive Car 1988;16:427-36.

4 Notcutt WG, Morgan RJM. Introducing patient-controlled analgesia for postoperative pain control into a district general hospital. Anaesthesia 1990;45:401-6.

Morgan M. The rational use of intrathecal and extradural opioids. Br f Anaesth 1989;63:165-88.

6 Ready LB, Oden R, Chadwick HS, et al. Development of an anesthesiology-based postoperative pain management service. Anesthesiology 1988;68:100-6.

McLintock TTC, Aiken H, Downie CFA, Kenny GNC. Postoperative analgesia requirements in patients exposed to positive intraoperative suggestions. $B M \mathcal{F}$ 1990;301:788-90. 8 Wall PD. The prevention of postoperative pain. Pain 1989;33:289-90.

\section{$\beta_{2}$ Agonists and asthma}

\section{Still the mainstay of symptomatic treatment}

Several recent publications have questioned the role of $\beta_{2}$ agonists in managing asthma. Earlier this month a meeting brought together doctors and representatives of pharmaceutical companies to discuss the topic. They concluded that $\beta_{2}$ agonists remain an effective and safe treatment. In general, the drugs should be used for symptomatic relief, and regular use should be reserved for patients who have already progressed to another prophylactic treatment (such as inhaled corticosteroids). Any problems with their use, the meeting decided, would be far exceeded by the disastrous effects of doctors or patients not using them.

Recent controversies now surround the safety of long term regular use of $\beta_{2}$ agonists, with particular worries about fenoterol and the place of the recently introduced long acting inhaled drugs. $\beta_{2}$ Agonists relax smooth muscle; the clinical importance of their other actions - inhibiting the release of mediators, modulating neural pathways, reducing microvascular leak, and increasing mucociliary clearance-remains unknown. Tachyphylaxis to the effects of $\beta_{2}$ agonists may be shown outside the lung but is not clinically relevant to the smooth muscle in the airways of asthmatic patients.

Anti-inflammatory effects have been claimed for the new long acting drug salmeterol. ${ }^{1}$ These effects have been shown for most $\beta_{2}$ agonists in vitro, release of inflammatory mediators being reduced in human chopped lung ${ }^{2}$ and mast cell preparations. ${ }^{3}$ Salmeterol and formoterol seem to have some extra inhibitory effects on macrophages, which are not blocked by $\beta_{2}$ blockers such as propranolol. In vivo these effects have been more difficult to show; studies are under way, but no convincing clinical evidence yet exists for any useful anti-inflammatory effect.

Most unwanted effects of $\beta_{2}$ agonists are well known and include cardiovascular, metabolic, and musculoskeletal effects. The $\beta_{2}$ agonist fenoterol has been under the closest surveillance because it has been linked to deaths from asthma in New Zealand. ${ }^{+5}$ This is most probably linked to the dose, with $200 \mu \mathrm{g}$ of drug from one puff of the standard fenoterol inhaler being equivalent to two puffs of salbutamol and terbutaline from standard inhalers. ${ }^{6} \mathrm{~A}$ greater effect per dose could lead to patients with more severe asthma being given fenoterol rather than another agent in places where use of fenoterol is high. In the United Kingdom little fenoterol is prescribed except as part of a combination inhaler with ipratropium bromide.

Several recent studies have suggested that regular use of $\beta_{2}$ agonists increases the responsiveness of airways to challenges with agents such as methacholine and histamine in children and adults. ${ }^{8-11}$ Problems could result if regular drugs were stopped or if increased narrowing of the airways stopped the penetration of the regular inhaled drug. This increased responsiveness has been shown in some studies but by no means all, and the time course is uncertain. Only one of these studies was properly placebo controlled ${ }^{9}$ and the changes in responsiveness have been small. Whether combination with an anti-inflammatory drug (such as an inhaled corticosteroid) would prevent any such hyperresponsiveness is not known. The paper by Sears and others is relevant to this question. ${ }^{10}$ It showed increased responsiveness despite most patients being prescribed inhaled steroids. This carefully designed study also, surprisingly, showed poorer clinical control of asthma in patients in New Zealand taking regular rather than intermittent fenoterol. The use of fenoterol as the $\beta_{2}$ agonist in the study complicated the interpretation, although participants at the meeting thought that any effect would probably not be limited to a single $\beta_{2}$ agonist. There was general frustration that the paper had been published with a simple comparison between two periods of treatment but no quantitative data. This made assessing its importance extremely difficult, and before influencing current treatment the results of this study need confirmation.

Recently the numbers of prescriptions for drugs for asthma and mortality from asthma have risen. Despite this a discus- 